(C) 1981. The Genetical Society of Great Britain

\title{
CROSSING OVER IN CULEX PIPIENS FATIGANS TRANSLOCATION HETEROZYGOTES
}

\author{
JOHANNA OHMANN* \\ Institut für Genetik, Johannes Gutenberg-Universität, Saarstraße 21, 6500 Mainz, \\ Federal Republic of Germany
}

Received 13.v.81

\section{INTRODUCTION}

THE frequency of crossing over and chiasmata in European strains of Culex pipiens L. is low (Moffett, 1936; Callan and Montalenti, 1947) when compared with many other species. In translocation lines, crossovers have either not been detected at all (Laven et al., 1971; Jost and Laven, 1971) or only at low frequencies (Dennhöfer, 1975); when occurring at higher frequencies, as in the subspecies $C$. p. fatigans, they are limited to the autosomes (Bhalla et al., 1974). The experiments described here show that in the strain Delhi of $C$. p. fatigans, crossing over regularly occurs also in translocated chromosomes carrying the sex determining factor.

\section{MATERIALS AND METHODS}

The experiments were conducted with various chromosome rearrangement lines of the strain Delhi of $C$. p. fatigans. The sex chromosomes are homologous in Culex (Stevens, 1911; Moffett, 1936; Callan and Montalenti, 1947; Gilchrist and Haldane, 1946; Kitzmiller, 1953; Mukherjee et al., 1970; Laven et al., 1971) and crossing over is basically possible in all three chromosome pairs. According to Gilchrist and Haldane $(1946,1947)$ sex determination is monogenic in Culex: males are heterozygous for the male-determining dominant and the female-determining recessive allele $(M / m)$, while females are $\mathrm{m} / \mathrm{m}$; the chromosome carrying the gene has been designated $\mathrm{I}$.

Neither the wild-type strain nor the lines carrying a chromosome rearrangement carried any marker genes. Therefore, to detect crossing over only the sex locus and the break points of the rearrangements could be used as markers. Since only males are heterozygous for both markers, recombinants can be detected only among the progeny of males heterozygous for a sex-linked rearrangement and not in the progeny of such females. Single crosses were made, with at least two or three normal females per male. When, in such a cross, a male fathered only egg rafts with partial lethality, it was considered to be most probably heterozygous for the chromosome rearrangement. However, significant conclusions about the karyotype can be drawn only after outcrossing the progeny of this male, since partial sterility has also been observed-though rarely-in animals without a chromosome rearrangement but with recessive lethals.

* Present address: Gesellschaft für Strahlen- und Umweltforschung, Abteilung für Molekulare Genetik, Grisebachstraße 8, 3400 Göttingen, Federal Republic of Germany. 
To distinguish between the different linkage possibilities of a reciprocal translocation (or an inversion or transposition), all animals coming from a partially lethal raft produced by a normal female and a male translocation heterozygote were mated to the normal stock. When half the females and half the males produce partially lethal and the others fully hatching rafts, the translocation is autosomal. When all or nearly all females resulting from one egg raft are partially sterile and none or only a few are normal, and when all or nearly all of their brothers are normal and none or only a few of them are partially sterile, then the translocation was linked to the female-determining allele of the sex locus $(m)$ in the father. While the sex linkage continues to be an $m$-linkage in the females, the few partially sterile males have inherited the $M$-linked translocation (fig. 1a). When, by contrast, all or nearly all the females are normal and all or nearly all the males are partially sterile, the translocation was $M$-linked in the father. In the female recombinants the translocation is of course $m$-linked (fig. 1b). Whether the partially sterile sons of a father with an $m$-linked translocation
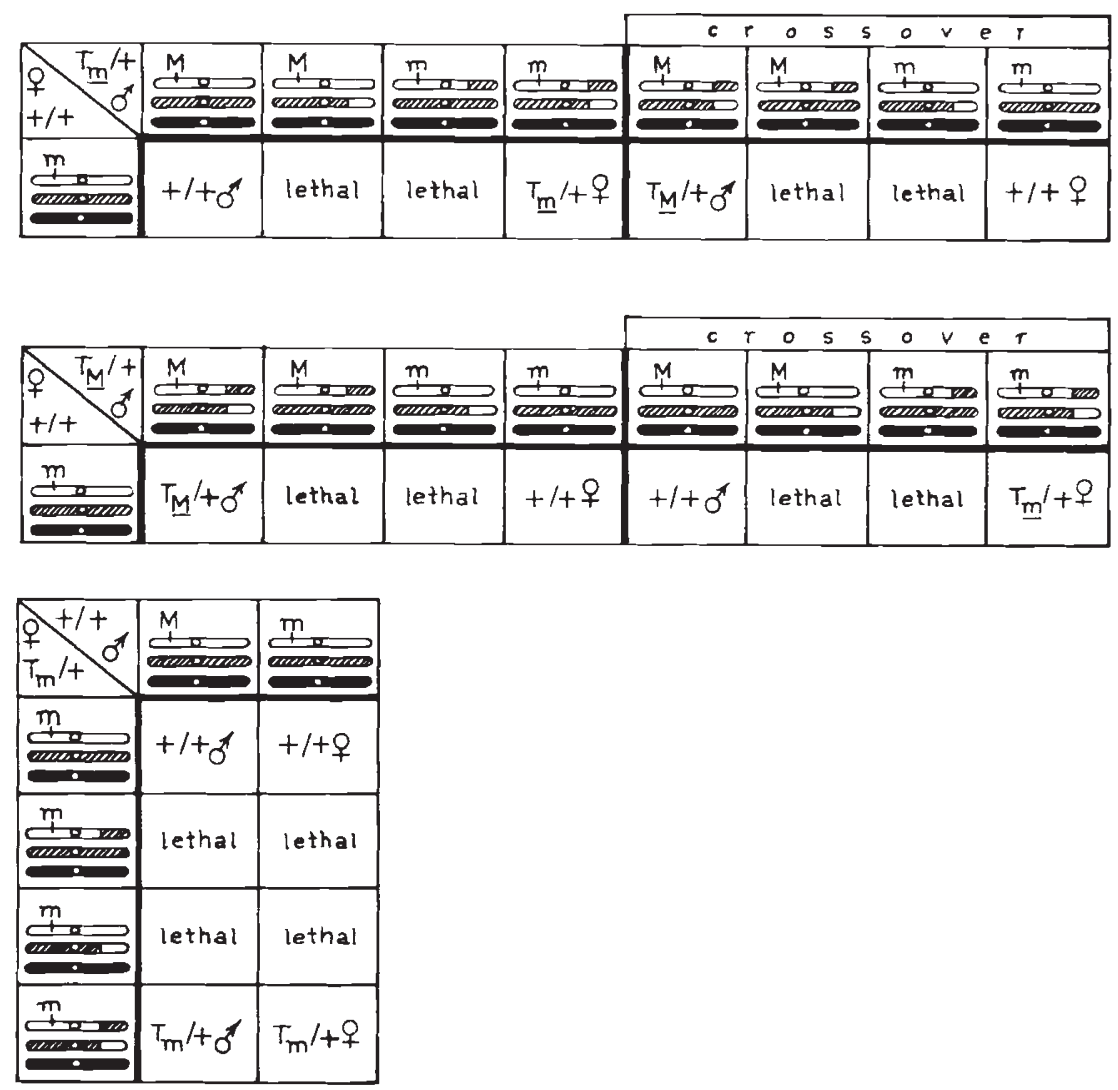

FIG. 1.-Crosses of translocation heterozygotes and normals. (a) Translocation, linked to the female-determining allele $(m)$, in the male parent. $\S$ (b) Translocation, linked to the male-determining allele $(M)$, in the male parent. $\S$ (c) Sex-linked translocation in the female parent partner. $\S$

$\S$ Adjacent-2-segregation neglected in all crosses. 
and the partially sterile daughters of a father with an $M$-linked translocation really are recombinants can be proved by mating their progenies to the normal stock, as before (figs. $1 \mathrm{~b}$ and $1 \mathrm{c}$ ).

For cytological analyses testes of 5-8 hours old pupae were fixed for 10-15 minutes in 3:1 alcohol : acetic acid and stained in aceto-orcein.

\section{RESUltS AND DISCUSSION}

Nine lines with a single sex-linked chromosome rearrangement were examined for crossing over between the sex locus and the break point. In seven of these lines heterozygotes produced aneuploid gametes at mean frequencies in the range of $42 \cdot 0-49 \cdot 6$ per cent. In the two remaining lines the mean partial sterility of heterozygotes reached only 35.2 and 38.9 per cent. Lines with low sterility were suspected of carrying rearrangements other than translocations. Cytological analyses were therefore carried out with the two lines having the lowest and the highest mean sterility. It was confirmed that line $G$ with the mean percentage of 49.6 per cent aneuploid gametes was a reciprocal translocation, and that line $P$ with $35 \cdot 2$ per cent mean sterility was an intrachromosomal transposition (shift). Intrachromosomal rearrangements have at least two break points in the chromosome concerned; all the odd numbers of crossovers between the two points lead to aneuploid gametes, and this is the only way that aneuploid gametes can occur. Viable recombinants result only if the sex locus is located outside the shifted or inverted region, and when crossing over occurs between the sex locus and the nearest break point. Therefore it is more accurate to say that in the experiments described crossing over between the sex locus and the nearest break point (in case there are two break points within the same chromosome, as in inversions, or three, as in shifts) was investigated.

Crossing over could be detected in all the lines, the mean rates ranging from $0 \cdot 51-11 \cdot 83$ per cent (fig. 2). This variation between the lines is to be expected if the locations of the respective break points differ in the lines. The continuous distribution of the mean values over a large range further indicates that the locations of the break points are the main cause of different crossing-over rates in the lines.

Variations within the lines, i.e., between individual males, are indicated by the standard deviations (fig. 2). When excluding from the calculations those progeny sibships where the survival rate and rate of reproducing animals were low, the figures are smaller than those given in fig. 2, but still significantly different. The different standard deviations of the lines could be explained by the close linkage of crossover-determining factors of different constitution to the break points. This alone can cause different deviations in different lines. This hypothesis of the basis of the deviations from the mean crossover rates does not contradict the earlier statement that the mean crossover rates depend on the distance between the break points and the sex locus, since there is incomplete correlation between the crossover rates and the order of magnitude of the respective deviations (fig. 2).

Heterogeneity in crossover rates has been found between different wild-type strains (Tadano and Brown, 1967; Dennhöfer, 1975) and geographical strains with induced rearrangements (Dennhöfer, 1975; Laven et al., 1971; Bhalla et al., 1974). In some of the strains tested there were 


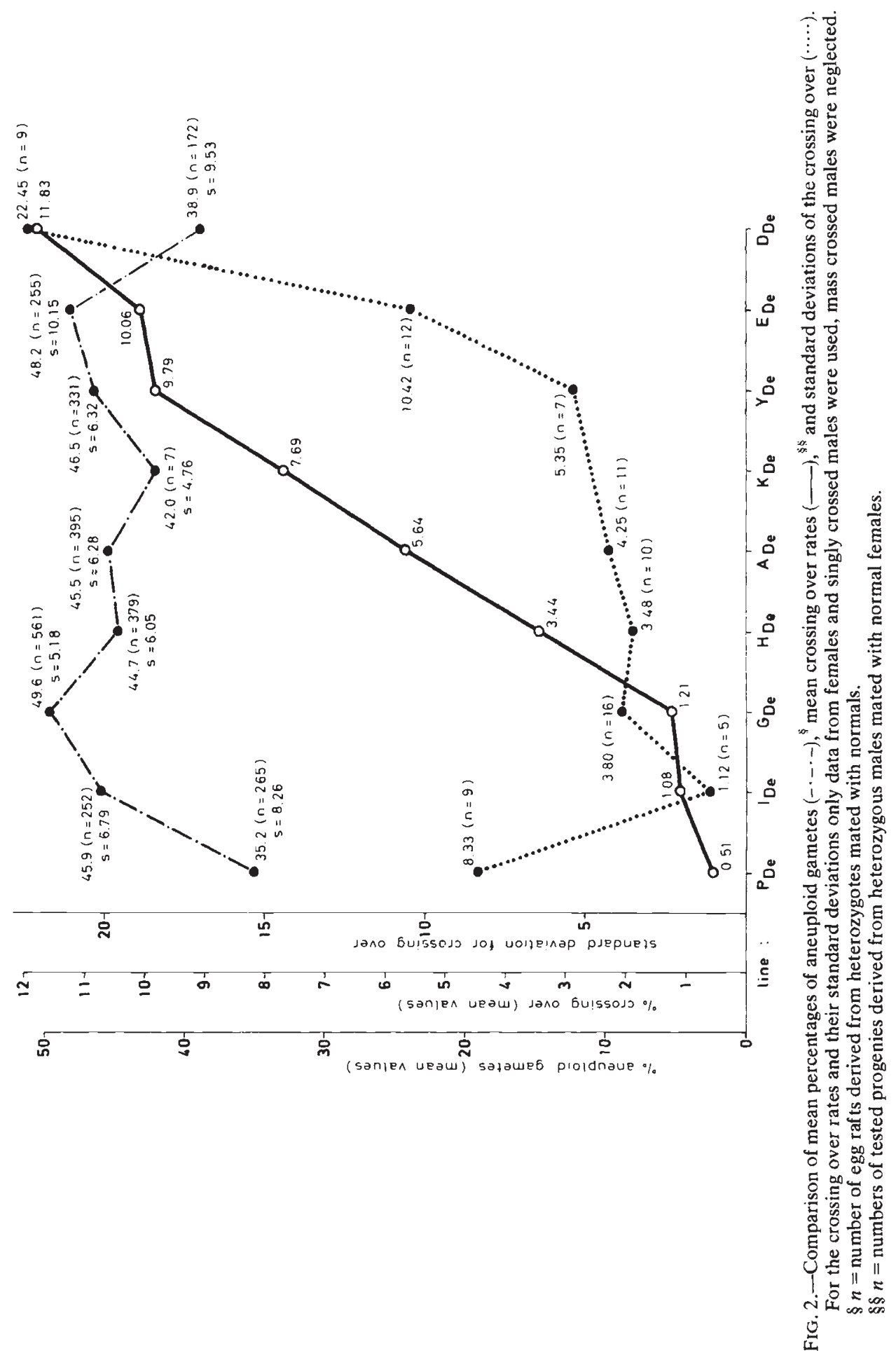


considerable crossover frequencies in the autosomes, but in the chromosome region around the sex-determining gene crossing over was absent or occurred at much lower frequency than in the experiments described in this paper. Thus the crossover rates of the total genomes and also those of distinct chromosomes or regions of chromosomes can differ in absolute and relative terms in different strains.

\section{REFERENCES}

BHALlA, S. C., CAJAibA, A. C. I., CARVAlho, W. M. P., AND SANTOS, J. M. 1974. Translocations, inversions and correlation of linkage groups to chromosomes in the mosquito, Culex pipiens fatigans. Canadian Journal of Genetics and Cytology, 16, 837-850.

CALlAN, H. G., AND MONTALENTI, G. 1947. Chiasma interference in mosquitoes. Journal of Genetics, 48, 119-134.

DENNHÖFER, L. 1975. Genlokalisation auf den larvalen Speicheldrüsenchromosomen der Stechmücke Culex pipiens L. Theoretical and Applied Genetics, 45, 279-289.

GILCHRIST, B. M., AND HALDANE, J. B. S. 1946. Sex linkage in Culex molestus, Experientia, 2,372 .

GILCHRIST, B. M., AND HALDANE, J. B. S. 1947. Sex linkage and sex determination in a mosquito, Culex molestus. Hereditas, 33, 175-190.

JOST, E., AND LAVEN, H. 1971. Meiosis in translocation heterozygotes in the mosquito Culex pipiens. Chromosoma, 35, 184-205.

KitZMilleR, J. B. 1953. Mosquito genetics and cytogenetics. Revista Brasileira de Malariologia e Doenças Tropicais, 5, 285-359.

LAVEN, H., MEYER, E., BIENIOK, R., GUILLE, G., AND OHMANN, J. 1971. Inherited semisterility for control of harmful insects. II. Degree of sterility and types of translocations in the mosquito Culex pipiens L. Experientia, 27, 968-969.

MOFFETT, A. A. 1936. The origin and behaviour of chiasmata. XIII. Diploid and tetraploid Culex pipiens. Cytologia, 7, 184-197.

MUKHERJEE, ANIL B., REES, D. M., AND MUKHERJEE, ASIT B. 1970. A comparative study of the mosquito karyotypes. Cytologia, 35, 57-62.

STEVENS, N. M. 1911. Further studies on heterochromosomes in mosquitoes. Biological Bulletin, 20, 109-120.

TADANO, T., AND BROWN, A. W. A. 1967. Genetical linkage relationships of DDT-resistance and dieldrin-resistance in Culex pipiens fatigans Wiedemann. Bulletin of the World Health Organisation, 36, 101-111. 